\title{
Preparation of planar and hydrophobic benzocyclobutene based dielectric material from biorenewable rosin
}

Fei $\mathrm{Fu}^{1,2}$, Dan Wang ${ }^{1,3}$, Minggui Shen ${ }^{1,3, *}$, Shibin Shang ${ }^{1,3}$, Zhanqian Song ${ }^{1, *}$, Jie Song ${ }^{4}$ 1 Institute of Chemical Industry of Forest Products, Chinese Academy of Forestry, Key Laboratory of Biomass Energy and Material, National Engineering Laboratory for Biomass Chemical Utilization, Key and Open Laboratory of Forest Chemical Engineering, State Forestry Administration, Nanjing 210042, Jiangsu Province, China

2 Co-Innovation Center of Efficient Processing and Utilization of Forest Resources, Nanjing Forestry University, Nanjing 210037, People’s Republic of China

3 Institute of New Technology of Forestry, Chinese Academy of Forestry, Beijing 100091, China

4 Department of Chemistry and Biochemistry, University of Michigan-Flint, Flint, Michigan 48502, United States

* Corresponding author: Minggui Shen; Zhanqian Song

Email: mingguishen@163.com; songzq@hotmail.com

Phone: 086-25-85482452.

Fax: 086-25-85482452.

\begin{abstract}
This is the author manuscript accepted for publication and has undergone full peer review but has not been through the copyediting, typesetting, pagination and proofreading process, which may lead to differences between this version and the Version of Record. Please cite this article as doi: 10.1002/app.48831
\end{abstract}

This article is protected by copyright. All rights reserved. 
A rosin-based monomer with thermally cross-linkable benzocyclobutene groups was synthesized in this study. The structure of the monomer was examined using mass spectroscopy (MS), Fourier transform infrared (FT-IR) spectroscopy and nuclear magnetic resonance (NMR) spectroscopy. An amorphous cross-linked network with dielectric constant of 2.71 and dielectric loss of 0.0012 at $30 \mathrm{MHz}$ was formed when the monomer was polymerized at high temperature $\left(>200{ }^{\circ} \mathrm{C}\right)$. The polymer film exhibits surface roughness ( $\mathrm{Ra}$ ) of $0.337 \mathrm{~nm}$ in a $5.0 \times 5.0 \mu \mathrm{m}^{2}$ area and the water contact angle of $110^{\circ}$. In addition, results from thermogravimetric analysis (TGA) indicate that the polymer has $\mathrm{T}_{5 \%}=402{ }^{\circ} \mathrm{C}$, and differential scanning calorimetry (DSC) measurements show that the glass transition temperature is at least $350{ }^{\circ} \mathrm{C}$. Results from nanoindentation tests show that the hardness and Young's modulus of the polymer are 0.418 GPa and 4.728 GPa, respectively. These data suggest that this new polymer may have potential applications in electronics and microelectronics.

\section{Introduction}

With the development of microelectronics, the sizes of individual devices have become progressively smaller. Scaling down generates problems such as interconnect signal delay (RC delay) that gives rise to propagation delay, cross-talk noise, and power dissipation. ${ }^{[1-4]}$ These problems have become an obstacle to further development within the microelectronics. The use of interconnect materials with low dielectric constant is 
one effective way to reduce RC delay. ${ }^{[5-8]}$ Therefore, the development of materials with low dielectric constant has received widespread attention. ${ }^{[1-8]}$ One method for decreasing the dielectric constant is to prepare porous materials because the dielectric constant of air is approximately 1 . However, high porosity will decrease the mechanical strength and increase water absorption, thus increasing the dielectric constant. ${ }^{[2]}$ Additionally, Long et al. synthesized polymers using ring-opening olefin metathesis polymerization (ROMP) of strained cyclic olefinic monomers. ${ }^{[9]}$ The material was found to have a low dielectric constant from free volume theory. An alternative method is to use intrinsically low-k polymers, such as SiLK, poly(benzoxazole)s, polyimides. ${ }^{[10-13]}$ Among these, benzocyclobutene (BCB) resins, as one family of low$\mathrm{k}$ polymers, have attracted much attention in recent years. ${ }^{[14-17]}$ The monomer benzocyclobutene could exhibit a ring-opening reaction in certain circumstances, yielding a cured resin. ${ }^{[14,16,17,18-23]}$ No catalyst is required and no volatile compounds are released during the curing process. Generally, the resulting $\mathrm{BCB}$ resins show excellent dielectric properties and thermal stability, low water absorption and thermal expansion coefficient. ${ }^{[24]}$ Correspondingly, BCB resins have been widely used in aerospace, electronics and microelectronics, in applications such as enameled wire varnish, large scale integrated circuits and composite materials. ${ }^{[25-27]}$

The development of bio-based polymers is promoted by growing concerns of long- 
term sustainability and the negative environmental footprint of petroleum-based polymer materials. ${ }^{[28-33]}$ Rosin acid is renewable, biodegradable and biocompatible, and it has a large hydrogenated phenanthrene ring structure, thus it could be used to synthesize and modify polymer materials. ${ }^{[34]}$ However, rosin containing conjugated double bonds can easily react with oxygen, which decreases the material quality, so methods including hydrogenation, disproportionation and polymerization are needed to modify rosin to improve its stability. ${ }^{[35]}$ Rosin derivatives may serve as alternatives to petroleum-based aromatic compounds or cycloaliphatic compounds that are generally used to modify polymers and improve their thermal and mechanical properties. ${ }^{[36]}$ The hydrogenated phenanthrene ring, as a characteristic functional group of rosin, significantly affects the hydrophobic and thermomechanical properties of polymers. ${ }^{\text {37- }}$ ${ }^{45]}$ Moreover, as the primary structural unit of target polymer, the huge hydrogenated phenanthrene ring structure can effectively block the winding of molecular segments, which increases the intermolecular spacing and free volume in polymer molecules. ${ }^{[46,47]}$ Therefore, the introduction of the hydrogenated phenanthrene ring might yield the BCB resins with good hydrophobic, thermomechanical and dielectric properties.

In this study, a new rosin-based monomer containing bibenzocyclobutene groups was synthesized using dehydroabietic acid (DA) as the raw material. The monomer synthesis route and monomer molecular structure are shown in Scheme 1. After ring 
opening polymerization at high temperature, a cross-linked network was formed in the monomer, providing good hydrophobic, mechanical and dielectric properties. These results indicate that the polymer is suitable as an encapsulation resin or dielectric material in electronics and microelectronics. Overall, the exhibited properties are comparable with other reported BCB based dielectric materials, while at the same time, this work is a good exploration for the application of bio-based materials in different areas.

Scheme 1. Procedure for the synthesis of new monomer and cured resin.

\section{Experimental Section}

\section{Materials}

Benzocyclobutene-4-boronic acid and 4-aminobenzocyclobutene were purchased from Chemtarget Technologies Co., Ltd. Dehydroabietic acid was obtained from Wuzhou chemical Co., Ltd. N-Bromosuccinimide (NBS), tripotassium phosphate, triethylamine, thionyl chloride and tetrakis(triphenylphosphine)palladium (0) were obtained from Aladdin Industrial Corporation. Ethanol, acetonitrile, mesitylene, dichloromethane, ethyl acetate and petroleum ether were purchased from Nanjing Chemical Reagent Co., Ltd. All chemicals were used without purification.

\section{Measurements}

This article is protected by copyright. All rights reserved. 
${ }^{1} \mathrm{H}$ and ${ }^{13} \mathrm{C}$ nuclear magnetic resonance (NMR) spectra were recorded at room temperature with a spectrometer (Bruker 400) using TMS as an internal standard with DMSO as a solvent. Fourier transform infrared (FT-IR) spectra were gathered with a Thermo Scientific Nicolet IS10 spectrometer (Nicolet) using attenuated total reflectance (ATR) measurements. Mass spectra from the compounds were recorded with a Waters Q-TOF Micro ${ }^{\mathrm{TM}}$ mass spectrometer (MS). Thermogravimetric analysis (TGA) was performed with a TG209F1 (NETZSCH, Germany) apparatus at a heating rate of $10{ }^{\circ} \mathrm{C} \min ^{-1}$ in $\mathrm{N}_{2}$ atmosphere. Differential scanning calorimetry (DSC) measurements were gathered with a Perkin Elmer Diamond Differential Scanning Calorimeter a heating rate of $10{ }^{\circ} \mathrm{C} \mathrm{min}^{-1}$ in $\mathrm{N}_{2}$ atmosphere. The contact angle of the cured resin was measured at room temperature with a dynamic contact angle measurement instrument (JC2000C) using the sessile drop method. Deionized water was used as the testing liquid. The surface toughness of the polymer film was measured using an atomic force microscope (AFM Shimadzu SPM-9600, Japan). The dielectric constant $(\mathrm{k})$ and dielectric loss $(\tan \delta)$ of the cured resin were measured at frequencies ranging from 1.0 to $30 \mathrm{MHz}$ at room temperature using a 4294A Precision Impedance Analyzer (Agilent). The mechanical properties of the cured resin were measured with a nanoindentation system (UNHT, Anton Paar). The phase structure of as-prepared product was characterized with X-ray diffraction (XRD, Bruker D8 advance with Cu 
$\mathrm{K} \alpha$ ). The scans were taken within the $2 \theta$ range between $5^{\circ}$ and $40^{\circ}$ and operated at an accelerating voltage of $40 \mathrm{kV}$ and an emission current of $40 \mathrm{~mA}$.

\section{Synthesis of Compound 1.}

Dehydroabietic acid (0.017 mol, $5.00 \mathrm{~g})$ was dissolved in anhydrous acetonitrile (337 mL), and NBS (0.031 mol, $5.54 \mathrm{~g})$ was added. The mixture was allowed to react in darkness at room temperature for $24 \mathrm{~h}$. The mixture was suction filtered, yielding a white solid that was dissolved in ethyl acetate $(50 \mathrm{~mL})$. Then the organic phase was washed with water (3 times with $50 \mathrm{~mL}$ ) and dried over anhydrous $\mathrm{Na}_{2} \mathrm{SO}_{4}$. After filtration and concentration, Compound $\mathbf{1}$ was purified using column chromatography with a mixture of petroleum ether and ethyl acetate as the eluent (5:1, v/v). Yield: 53\%. ${ }^{1} \mathrm{H}$ NMR (400 MHz, DMSO) $\delta 12.20(\mathrm{~s}, 1 \mathrm{H}), 7.36$ (s, 1H), $7.00(\mathrm{~s}, 1 \mathrm{H}) .{ }^{13} \mathrm{C}$ NMR $(101$ MHz, DMSO) $\delta 179.2$ (m), 149.2 (s), 143.2 (s), 134.5 (s), 128.0 (s), 127.2 (s), 120.8 (m), 46.2 (s), 44.2 (s), 37.5 (s), 36.5 (s), 36.1 (s), 31.9 (s), 28.9 (s), 24.6 (s), 22.7 (s), 22.6 (s), 20.8 (m), 18.0 (s), 16.3 (s); MS (ESI) m/z 377 [M - H].

\section{Synthesis of Compound 2.}

Compound 1 (1.00 mmol, 0.379 g), tripotassium phosphate (2.00 mmol, 0.425 g) and benzocyclobutene-4-boronic acid (1.25 mmol, $0.185 \mathrm{~g}$ ) were dissolved in a water/ethanol mixture (6 $\mathrm{mL}, 1: 1, \mathrm{v} / \mathrm{v})$ in a $\mathrm{N}_{2}$ atmosphere. Tetrakis(triphenylphosphine)palladium (0) (0.01 mmol, 0.0116 g) was added, and the 
mixture was subsequently heated at $60^{\circ} \mathrm{C}$ for $10 \mathrm{~h}$. The mixture was allowed to cool to room temperature and suction filtered with diatomite. The filtrate then was extracted with ethyl acetate (2 times with $30 \mathrm{~mL}$ ). The organic phases were combined, washed with water (3 times with $50 \mathrm{~mL}$ ), dried over anhydrous $\mathrm{Na}_{2} \mathrm{SO}_{4}$, filtered and concentrated to yield the crude product. Compound $\mathbf{2}$ was purified using column chromatography with a mixture of petroleum ether and ethyl acetate as the eluent (5:1, v/v). Yield: 85\%. ${ }^{1} \mathrm{H}$ NMR (400 MHz, DMSO) $\delta 12.16$ (s, 1H), 7.10 (d, J = 7.5 Hz, 1H), 7.02 (dd, $J=7.5,0.9 \mathrm{~Hz}, 1 \mathrm{H}), 7.00$ (s, $1 \mathrm{H}), 6.93$ (s, 1H), 6.91 (s, 1H), 3.18 (s, 4H). ${ }^{13} \mathrm{C}$ NMR (101 MHz, DMSO) $\delta 179.4$ (s), 146.27 (s), 144.9 (s), 143.4 (s), 142.5 (s), 140.6 (s), 138.9 (s), 133.5 (s), 127.7 (s), 125.4 (s), 125.3 (s), 123.2 (s), 122.0 (s), 46.3 (s), 44.6 (s), 37.7 (s), 36.3 (s), 36.2 (s), 29.2 (s), 29.0 (s), 28.9 (s), 28.3 (s), 24.8 (s), 24.2 (s), 24.0 (s), 21.1 (s), 18.1 (s), 16.3 (s); MS (ESI) m/z 401 [M - H].

\section{Synthesis of Monomer 3.}

Compound 2 (4.97 mmol, $2.00 \mathrm{~g}$ ) was dissolved in dichloromethane (15 mL). Thionyl chloride (9.94 mmol, $1.18 \mathrm{~g}$ ) was added slowly. After the solution was heated to reflux while stirring for $4.0 \mathrm{~h}$, excessive thionyl chloride was removed by distillation, yielding the reaction crude. 4-aminobenzocyclobutene (5.96 mmol, $0.71 \mathrm{~g}$ ) was dissolved in dichloromethane (15 mL), and triethylamine (14.91 mmol, $1.51 \mathrm{~g}$ ) was added. The crude was dissolved in dichloromethane $(5.0 \mathrm{~mL})$, and the solution was 
added dropwise at room temperature. The mixture was stirred for $12 \mathrm{~h}$ at room temperature, and $10 \% \mathrm{HCl}(20 \mathrm{~mL})$ was added to annihilate. Then the water phase was extracted with ethyl acetate (2 times with $30 \mathrm{~mL}$ ). The organic phases were combined, washed with water (3 times with $50 \mathrm{~mL}$ ), dried over anhydrous $\mathrm{Na}_{2} \mathrm{SO}_{4}$, filtered and concentrated to yield the crude product. Monomer $\mathbf{3}$ was purified using column chromatography with a mixture of petroleum ether and ethyl acetate as the eluent (5:1, v/v). Yield: 92\%. ${ }^{1} \mathrm{H}$ NMR (400 MHz, DMSO) $\delta 9.20$ (s, 1H), 7.39 (s, 1H), 7.29 (d, J = $7.9 \mathrm{~Hz}, 1 \mathrm{H}), 7.10$ (d, $J=7.4 \mathrm{~Hz}, 1 \mathrm{H}), 7.02$ (s, 1H), 7.00 (s, 1H), 6.97 (d, $J=8.3 \mathrm{~Hz}$, 1H), 6.95 (s, 1H), 6.92 (s, 1H), 3.17 (s, 4H), 3.07 (s, 4H). ${ }^{13} \mathrm{C}$ NMR (101 MHz, DMSO) $\delta 176.3$ (s), 146.7 (s), 144.9 (s), 144.8 (s), 143.5 (s), 142.5 (s), 140.6 (s), 139.9 (s), 138.9 (s), 138.2 (s), 133.8 (s), 127.7 (s), 125.4 (s), 125.3 (s), 123.1 (s), 122.3 (s), 122.0 (s), 120.0 (s), 116.0 (s), 47.4 (s), 44.2 (s), 37.2 (s), 36.7 (s), 35.8 (s), 29.2 (s), 29.1 (s), 28.9 (s), 28.7 (s), 28.6 (s), 28.4 (s), 24.9 (s), 24.3 (s), 23.9 (s), 20.6 (s), 18.5 (s), 16.3 (s); MS (ESI) $m / z 526[\mathrm{M}+\mathrm{Na}]^{+}$.

\section{Preparation of BCB polymers}

The rosin-based BCB resin was prepared by placing Monomer 3 directly into a glass mold. After degassing in a vacuum oven at $160{ }^{\circ} \mathrm{C}$ for $1.0 \mathrm{~h}$, the mold was heated stepwise at $180^{\circ} \mathrm{C}$ for $1.0 \mathrm{~h}, 200{ }^{\circ} \mathrm{C}$ for $4.0 \mathrm{~h}, 210^{\circ} \mathrm{C}$ for $4.0 \mathrm{~h}, 230^{\circ} \mathrm{C}$ for $4 \mathrm{~h}, 250{ }^{\circ} \mathrm{C}$ for $6 \mathrm{~h}$ and $270{ }^{\circ} \mathrm{C}$ for $1.0 \mathrm{~h}$ (under nitrogen atmosphere). The cured sample was used 
to measure the dielectric properties and for nanoindentation tests.

Monomer 3 (100 mg) was dissolved in mesitylene $(1.0 \mathrm{~mL})$ and refluxed for $10 \mathrm{~h}$ to obtain oligomers. The oligomer was spin-coated on a silicon wafer to form a smooth film, which was dried for $24 \mathrm{~h}$ at room temperature in a vacuum oven. The silicon wafer was placed in a tube furnace and heated stepwise at $180{ }^{\circ} \mathrm{C}$ for $1.0 \mathrm{~h}, 200{ }^{\circ} \mathrm{C}$ for $4.0 \mathrm{~h}$, $210^{\circ} \mathrm{C}$ for $4.0 \mathrm{~h}, 230{ }^{\circ} \mathrm{C}$ for $4 \mathrm{~h}, 250{ }^{\circ} \mathrm{C}$ for $6 \mathrm{~h}$ and $270{ }^{\circ} \mathrm{C}$ for $1.0 \mathrm{~h}$. After allowing the wafer to cool to room temperature, the sample was used to measure the surface toughness of the film.

\section{Results and Discussion}

\section{Synthesis and characterization}

Monomer 3 was prepared via three steps using dehydroabietic acid as the feedstock as shown in Scheme 1. Dehydroabietic acid was reacted to obtain a brominated intermediate (Compound 1), which was then reacted with benzocyclobutene-4-boronic acid to afford Compound 2 via a Suzuki coupling reaction. Taking the carboxyl group as the active site, Compound 2 was then reacted with 4aminobenzocyclobutene to yield a rosin monomer with two BCB groups (Monomer 3) via an amide reaction. The chemical structures of the compounds were confirmed by ${ }^{1} \mathrm{H}$ NMR, ${ }^{13} \mathrm{C}$ NMR and MS measurements (see in Support Information). Under elevated temperature, there is no difference in reactivity between the two BCB 
groups. Moreover, coupling to form an 8-member ring and ring-opening polymerization are both possible. Scheme 1 illustrated one kind of the structure of the polymer.

The chemical structure of Monomer 3 was characterized by ${ }^{1} \mathrm{HNMR},{ }^{13} \mathrm{C}$ NMR, and FT-IR spectra (Figures 1-3). One can see from Figure 1 that the peak at $9.20 \mathrm{ppm}$ derives from proton in the -CONH- groups; the peaks at 7.39-6.92 ppm are attributed to protons in the benzene ring; the characteristic peaks from the protons on the fourmembered ring of benzocyclobutene appear at $3.17 \mathrm{ppm}$ and $3.07 \mathrm{ppm}$, and the signals from $3.0 \mathrm{ppm}$ to $0.5 \mathrm{ppm}$ are assigned to protons attached to the hydrogenated phenanthrene ring. ${ }^{[48]}$ The peak at $176.3 \mathrm{ppm}$ in the ${ }^{13} \mathrm{C}$ NMR spectrum (Figure 2) belongs to carbon atom in the amide group; the peaks from carbon atoms in the benzene ring appear at 146.7, 144.9, 144.8, 143.5, 142.5, 140.6, 139.9, 138.9, 138.2, 133.8, $127.7,125.4,125.3,123.1,122.3,122.0,120.0$ and $116.0 \mathrm{ppm}$; the signals from carbon atoms in cyclobutene are located at 29.1, 28.9, 28.7, 28.6 ppm, and the remaining peaks are attributed to carbon atoms in the hydrogenated phenanthrene ring. FT-IR spectra from Monomer 3 are shown in Figure 3. The peak at $3428 \mathrm{~cm}^{-1}$ belongs to the $\mathrm{N}-\mathrm{H}$ stretching vibration, and the absorption peak at $1467 \mathrm{~cm}^{-1}$ is ascribed to the in-plane ring stretching vibration of $\mathrm{C}-\mathrm{H}$ in the four-member ring of benzocyclobutene group. ${ }^{\text {[9] }}$ Thus, all data are consistent with the chemical structure of Monomer 3. 
Figure 1. ${ }^{1} \mathrm{H}$ NMR spectra of Monomer 3.

Figure 2. ${ }^{13} \mathrm{C}$ NMR spectra of Monomer 3.

Figure 3. FT-IR spectra of Monomer 3 and resin.

\section{Curing behavior}

The curing behavior of Monomer 3 was characterized using DSC, and the result are shown in Figure 4. The endothermic peak indicates melting at $180{ }^{\circ} \mathrm{C}$. An exothermic peak is observed when the temperature increases above $200{ }^{\circ} \mathrm{C}$, which is attributed to a ring-opening reaction in benzocyclobutene units. Moreover, the exothermic peak temperature $\mathrm{T}_{\max }=258{ }^{\circ} \mathrm{C}$. The curing behavior of the monomer is similar that observed in benzocyclobutene containing compounds. ${ }^{[33]}$ The polymerization degree of the monomer was estimated from the DSC trace. After the resin was heated from $40{ }^{\circ} \mathrm{C}$ to $300{ }^{\circ} \mathrm{C}$ at $10{ }^{\circ} \mathrm{C} \mathrm{min}{ }^{-1}$ in $\mathrm{N}_{2}$, the DSC trace shows that no exothermic peak is observed, indicating complete polymerization. ${ }^{[27]}$

Figure 4. DSC curves of Monomer 3 and resin gathered at a heating rate of

$$
10{ }^{\circ} \mathrm{C} \min ^{-1}
$$

The progress of the curing reaction of Monomer 3 was examined using FT-IR

This article is protected by copyright. All rights reserved. 
spectroscopy. FT-IR spectra for from monomer and the cured resin are shown in Figure

3. The characteristic peaks for the benzocyclobutene group at $1467 \mathrm{~cm}^{-1}$ disappear after the curing reaction. Moreover, the characteristic peak of BCB monomers at $1467 \mathrm{~cm}^{-1}$ is transferred to $1500 \mathrm{~cm}^{-1}$ after the polymerization. ${ }^{[46]}$ This result suggests that the monomer has been fully converted to a cured resin.

\section{Thermal stability}

The thermostability of the cured resin was investigated using TGA. Figure 5a shows a TGA curve from the cured resin when heated at $10{ }^{\circ} \mathrm{C} \min ^{-1}$ in $\mathrm{N}_{2}$. The $\mathrm{T}_{5 \%}$ value is chosen as a measure of thermal stability, which represents the temperature at five percent mass loss. As shown in Figure $5 \mathrm{~b}, \mathrm{~T}_{5 \%}, \mathrm{~T}_{10 \%}$, and $\mathrm{T}_{50 \%}$ of the cured resin are $402{ }^{\circ} \mathrm{C}, 426^{\circ} \mathrm{C}$, and $485^{\circ} \mathrm{C}$, respectively; the residual yield of the cure resin is $14.6 \%$ at $800{ }^{\circ} \mathrm{C}$. It is known that the structural unit of the polymer is primarily composed of rigid benzene ring and hydrogenated phenanthrene ring, so such high thermal stability may result from the planar structure of either the phenanthrene or phenyl rings that give room for ordered packing of the rigid structures. ${ }^{[40]}$ Additionally, the BCB groups can be used as the cross-linking unit during curing. It is well known that the cross-linking structure can effectively improve the thermal stability of polymers. ${ }^{[36]}$ Moreover, the glass transition temperature $\left(\mathrm{T}_{\mathrm{g}}\right)$ of the cured resin was investigated using DSC. Figure 6 shows the $\mathrm{T}_{\mathrm{g}}$ value of the cured resin when heating at $10{ }^{\circ} \mathrm{C} \min ^{-1}$ in $\mathrm{N}_{2}$. The DSC 
trace indicates no evidence of a glass transition at temperatures ranging from 50 to $350{ }^{\circ} \mathrm{C}$.

Figure 5. Thermal stability of the cured resin: (a) TG curve and (b) the residual yield of the resin at each temperature.

Figure 6. DSC curve of the cured resin.

\section{Mechanical properties}

The mechanical properties of the cured resin were determined using a nanoindentation system. The hardness and Young's modulus of the polymer were calculated from a force vs. indentation depth curve. Young's modulus can be calculated using eq (1): ${ }^{[50-52]}$

$$
\frac{1}{\mathrm{E}_{\mathrm{r}}}=\frac{1-v}{\mathrm{E}}+\frac{1-v_{\mathrm{i}}}{\mathrm{E}_{\mathrm{i}}}
$$

where $E_{i}$ and $v_{i}$ are Young's modulus (1141 GPa) and Poisson's ratio (0.07) of a diamond indenter, $E_{r}$ is the reduced elastic modulus, E and $v$ are Young's modulus and Poisson's ratio of the sample, respectively. We used $v=0.34$ for polymer materials. ${ }^{[53]}$ The sample's hardness $(\mathrm{H})$ can be determined by dividing the peak load $\left(P_{\max }\right)$ by contact area $(A)$, eq $(2):^{[50-52]}$

$$
\mathrm{H}=\frac{P_{\max }}{\mathrm{A}}
$$


The results of the four tests are shown in Figure 7. As shown in Figure 7a, the pressure and indentation depth curves nearly overlap. Moreover, the values of hardness and Young's modulus for the resin are similar (Figures 7b and 7c). The results show that the cured resin has an average hardness of $0.418 \mathrm{GPa}$ and a Young's modulus of $4.728 \mathrm{GPa}$. Some researchers have noted that the introduction of a hydrogenated phenanthrene ring effectively improves the mechanical properties of polymer (e.g., silicone rubber, polylactic acid and epoxy resin). ${ }^{[36,42,54]}$ Therefore, the introduction of a hydrogenated phenanthrene ring improves the mechanical properties of the polymer, and the polymer has a cross-linked structure, so the polymer has excellent mechanical properties.

Figure 7. Results from nanoindentation tests for the cured resin: (a) pressure vs. indentation depth curves, (b) hardness and (c) Young's modulus of the resin

\section{Surface roughness}

The surface roughness of the polymer cast on a silicon wafer was investigated using an AFM. Both planar graph and stereogram are shown in Figure 8. The difference between the maximum and minimum thickness is $3.1 \mathrm{~nm}$. Moreover, the measurements show that the average surface roughness $(\mathrm{Ra})$ of the cured resin is $0.337 \mathrm{~nm}$ within a $5.0 \times 5.0 \mu \mathrm{m}^{2}$ area, and the Ra value of cured resin could be comparable to the reported BCB resins, such as fluorinated BCB resins ${ }^{[27]}$, siloxane-based BCB resins ${ }^{[2]}$ and BCB 
resins containing bulk groups ${ }^{[46]}$. It is well known that the BCB-based resin exhibits good surface roughness, ${ }^{[27,33,46]}$ and the introduction of rosin did not affect the surface smoothness of the resin. We think rosin and BCB are both rigid structures, so they have a certain degree of compatibility. Therefore, there is no obvious shrinkage or expansion during curing of the rosin-based BCB monomer. In addition, the surface roughness is more important for the materials utilized in electronics and microelectronics, because low surface roughness implies that an array with high quality can be easily produced on the film surface. ${ }^{[33]}$

Figure 8. AFM images of the cured resin film: (a) planar graph and (b) stereogram.

\section{Hydrophobic property}

Hydrophobicity is a more important parameter for the application of high performance material in the electronics and microelectronics, because it governs moisture adsorption and deterioration of dielectric properties. ${ }^{[27]}$ The hydrophobicity of the cured resin was investigated using contact angle tests with deionized water. The water contact angle is found to be $110^{\circ}$ (Figure 9). It is noted that the water contact angle of cured resin is batter than the reported $\mathrm{BCB}$ resins, such as, $96^{\circ[33]}, 102^{\circ[27]}$ and $107^{\circ[46]}$. Additionally, a resin disk with a thickness of $2.0 \mathrm{~mm}$ and a diameter of 12.0 mm was kept in boiling water for 2 days, exhibiting a water uptake of $0.32 \%$. The result 
indicates the resin has good hydrophobicity because of the introduction of rosin acid. As a hydrophobic group, the introduction of the hydrogenated phenanthrene ring can improve the hydrophobicity of polymeric materials. ${ }^{[44,45]}$ Moreover, the polymer structure has a slightly flexible chain segment, and the rigid structure will improve the hydrophobicity of polymer. ${ }^{[44]}$

Figure 9. Contact angle of water on the cured resin.

\section{Dielectric properties}

Dielectric properties are also important parameters for materials applied in electronics packaging. The dielectric properties of the cured resin were measured using the capacitance method, and the results are shown in Figure 10. Electromagnetic waves propagate with a higher velocity when dielectric constant is lower, leading to lower line capacitance per unit length and higher characteristic impedance for a fixed conductor cross section. ${ }^{[46]}$ Figure 10 shows that the cured resin dielectric constant (k) of 2.71 and dielectric loss $(\tan \delta)$ of 0.0012 at $30 \mathrm{MHz}$. Moreover, the average k value of 2.84 and $\tan \delta$ of 0.012 frequencies ranging from 1.0 to $30 \mathrm{MHz}$ at room temperature. One should note that the $\mathrm{k}$ value of the cured resin is comparable to the commercially available organic low-k materials, such as polyimides (3.1-3.4), ${ }^{[11,12]}$ SILK resins $(2.65)^{[10]}$ and polycyanate esters $(2.61-3.12) .^{[55]}$ 
Figure 10. Dielectric constant and dielectric loss of the cured resin.

The good dielectric property of the cured resin can be explained by the Debye equation, as shown in eq (3): ${ }^{[8]}$

$$
\frac{\mathrm{k}-1}{\mathrm{k}+2}=\frac{4 \pi}{3} \mathrm{~N}\left(\alpha_{\mathrm{e}}+\alpha_{\mathrm{d}}+\frac{u}{3 k_{b} T}\right)
$$

where $k$ is dielectric constant, $N$ is the number density of dipoles, $\alpha_{e}$ is the electric polarization, $\alpha_{d}$ is the distortion polarization, $\mu$ is the orientation polarization related to the dipole moment, $k_{b}$ is Boltzmann's constant, and $T$ is the temperature. The rosin structure is primarily composed of C-C bonds, so the introduction of rosin can decrease the electron density and make the molecule difficult to polarize, thus decreasing $\alpha_{d}$ and $\alpha_{e}{ }^{[46]}$ Additionally, the bulky hydrogenated phenanthrene ring structure moieties prevent molecular stacking and increase the free volume of the polymer, thus diminishing $N$ and $\mu .^{[8,46]}$ The reduction of all the factors $\left(\alpha_{d}, \alpha_{e}, N\right.$ and $\mu$ ) in eq (3) indicates that the resin has good dielectric property.

The XRD patterns in Figure 11 indicate that the cured resin is essentially amorphous and molecular stacking is prevented. The XRD peak at $2 \theta=15.0^{\circ}$ corresponds to a d value of $0.590 \mathrm{~nm}$ in the cured resin. Such large d spacing confirms the existence of a large free volume in the polymer, so the cured resin exhibits low-k value. ${ }^{[7]}$ 
Figure 11. X-ray diffraction (XRD) patterns of the cured resin (film and powder).

\section{Conclusion}

In summary, a rosin-based dibenzocyclobutene polymerizable monomer was designed and successfully synthesized. A cross-linked network was formed after polymerization, and the polymerized material exhibited an average dielectric constant of 2.84 and dielectric loss of 0.012 frequencies ranging from 1.0 to $30 \mathrm{MHz}$ at room temperature. The cured resin had good thermal ability with $\mathrm{T}_{5 \%}$ of $402{ }^{\circ} \mathrm{C}$ and no glass transition at temperature below $350{ }^{\circ} \mathrm{C}$. In addition, the cured resin showed excellent film uniformity and good hydrophobicity with the surface roughness (Ra) of $0.337 \mathrm{~nm}$ in a $5.0 \times 5.0 \mu \mathrm{m}^{2}$ area and the water contact angle of $110^{\circ}$. The cured resin possessed good mechanical properties, with hardness, Young’s modulus of $0.418 \mathrm{GPa}$, 4.728 GPa, respectively. These results indicate that the thermosetting polymer derived from rosin acid is suitable for use in electronics and microelectronics.

\section{Supporting Information}

Supporting information is available from the Wiley Online Library or from the author. Figures S1 and S2 show ${ }^{1} \mathrm{H}$ NMR and ${ }^{13} \mathrm{C}$ NMR spectra from Compound 1, respectively. Figures S3 and S4 show ${ }^{1} \mathrm{H}$ NMR and ${ }^{13} \mathrm{C}$ NMR spectra from Compound 2, respectively. Figures S5 and S6 show ${ }^{1} \mathrm{H}$ NMR and ${ }^{13} \mathrm{C}$ NMR spectra from Monomer 3, respectively. 
Figures S7-S9 show mass spectra of Compound 1, Compound 2, and Monomer 3, respectively. Scheme S1 shows thermal polymerization reaction of Monomer 3.

\section{Acknowledgments}

The authors express their gratitude for the financial support provided by the Fundamental Research Funds of CAF (CAFYBB2017SY035), Natural Science Foundation of Jiangsu Province of China (BK20150071) and National Science Foundation of China (31500487).

\section{Conflict of Interest}

The authors declare no conflict of interest.

\section{References}

[1] Y. Huang, S. Zhang, H. Hu, X. Wei, H. Yu, J. Yang, Polym. Advan. Technol. 2017, 28, 1480.

[2] Y. Cheng, W. Chen, Z. Li, T. Zhu, Z. Zhang, Y. Jin, RSC Adv. 2017, 7, 14406.

[3] S. Zhang, H. Hu, H. Yu, Y. Huang, J. Yang, Macromol. Res. 2017, 25, 381.

[4] F. He, K. Jin, J. Wang, Y. Luo, J. Sun, Q. Fang, Macromol. Chem. Phys. 2015, 216, 2302.

[5] Y. Huang, S. Zhang, H. Hu, X. Wei, H. Yu, J. Yang, J. Polym. Sci. Part A: Polym. Chem. 2017, 55, 1920.

[6] B. Zhao, C. Zhao, C. Wang, C. B. Park, J. Mater. Chem. C. 2018, 6, 3065.

[7] C. Yuan, J. Wang, K. Jin, S. Diao, J. Sun, J. Tong, Q. Fang, Macromolecules 2014, 47, 6311.

[8] C. Yuan, K. Jin, K. Li, S. Diao, J. Tong, Q. Fang, Adv. Mater. 2013, 25, 4875.

[9] T. M. Long, T. M. Swager, J. Am. Chem. Soc. 2003, 125, 14113.

[10] S. J. Martin, J. P. Godschalx, M. E. Mills, E. O. S. Ii, P. H. Townsend, Adv. Mater. 2000, 12, 1769.

[11] G. Maier, Prog. Polym. Sci. 2001, 26, 3.

This article is protected by copyright. All rights reserved. 
[12] Y. Watanabe, Y. Shibasaki, S. Ando, M. Ueda, Polym. J. 2006, 38, 79.

[13] W. Volksen, R. D. Miller, G. Dubois, Chem. Rev. 2010, 110, 56.

[14] J. Tong, S. Diao, K. Jin, C. Yuan, J. Wang, J. Sun, Q. Fang, Polymer 2014, 55, 3628.

[15] Y. Cheng, J. Yang, Y. Jin, D. Deng, F. Xiao, Macromolecules 2012, 45, 4085.

[16] K. Cao, L. Yang, Y. Huang, G. Chang, J. Yang, Polymer 2014, 55, 5680.

[17] L. S. Tan, N. Venkatasubramanian, P. T. Mather, M. D. Houtz, C. L. Benner, J. Polym. Sci. Part A: Polym. Chem. 1998, 36, 2637.

[18] C. O. Hayes, P. H. Chen, R. Thedford, C. J. Ellison, G. Dong, C. Willson, Macromolecules 2016, 49, 3706.

[19] Z. J. Wei, Y. W. Xu, L. Zhang, M. M. Luo, Chinese. Chem. Lett. 2014, 25, 1367.

[20] A. P. Gies, L. Spencer, N. J. Rau, P. Boopalachandran, M. A. Rickard, K. L. Kearns, N. T. McDougal, Macromolecules 2017, 50, 2304.

[21] J. Yang, S. Liu, F. Zhu, Y. Huang, B. Li, L. Zhang, J. Polym. Sci. Part A: Polym. Chem. 2015, 49, 381.

[22] J. Yang, Y. Cheng, F. Xiao, Eur. Polym. J. 2012, 48, 751.

[23] M. F. Farona, Prog. Polym. Sci. 1996, 21, 505.

[24] Y. Cheng, S. Tian, Y. Shi, W. Chen, Z. Li, T. Zhu, Z. Zhang, Eur. Polym. J. 2017, 95, 440.

[25] Y. Cheng, L. Kong, Z. Ren, T. Qi, High Perform. Polym. 2013, 25, 980.

[26] L. Yang, K. Cao, Y. Huang, G. Chang, F. Zhu, J. Yang, High Perform. Polym. 2014, 26, 463.

[27] S. Tian, J. Sun, K. Jin, J. Wang, F. He, S. Zheng, Q. Fang, ACS Appl. Mater. Inter. 2014, 6, 20437.

[28] J. Wang, C. Lu, Y. Liu, C. Wang, F. Chu, Ind. Crop. Prod. 2018, 124, 244.

[29] J. Yu, Y. Liu, X. Liu, C. Wang, J. Wang, F. Chu, C. Tang, Green Chem. 2014, 16, 1854

[30] X. Yan, Z. Zhai, Z. Song, S. Shang, X. Rao, Ind. Crop. Prod. 2017, 108, 371.

[31] C. Lu, J. Yu, C. Wang, J. Wang, F. Chu, Carbohyd. Polym. 2018, 188, 128.

[32] Q. Li, X. Huang, H. Liu, S. Shang, Z. Song, J. Song, ACS Sustain. Chem. Eng. 2017, 5, 10002.

This article is protected by copyright. All rights reserved. 
[33] F. He, K. Jin, Y. Wang, J. Wang, J. Zhou, J. Sun, Q. Fang, ACS Sustain. Chem. Eng. 2017, 5, 2578.

[34] H. Zhang, X. Huang, J. Jiang, S. Shang, Z. Song, RSC Adv. 2017, 7, 42541.

[35] D. Zhang, D. Zhou, X. Wei, J. Liang, X. Chen, L. Wang, J. Supercrit. Fluid. 2017, 125, 12.

[36] X. Yang, Q. Li, Z. Li, X. Xu, H. Liu, S. Shang, Z. Song, ACS Sustain. Chem. Eng. 2019, 7, 4964.

[37] V. Singh, S. Joshi, T. Malviya, Int. J. Biol. Macromol. 2018, 112, 390.

[38] P. Carbonell-Blasco, Miguel Martín-Martínez. José, I. Antoniac, Int. J. Adhes. Adhes. 2013, 42, 11.

[39] B. Liu, J. Nie, Y. He, Int. J. Adhes. Adhes. 2016, 66, 99.

[40] R. A. El-Ghazawy, A. M. El-Saeed, H. I. Al-Shafey, A. M. Abdul-Raheim, M. A. El-Sockary, Eur. Polym. J. 2015, 69, 403.

[41] K. Huang, J. Zhang, M. Li, J. Xia, Y. Zhou, Ind. Crop. Prod. 2013, 49, 497.

[42] H. Wang, X. Liu, B. Liu, J. Zhang, M. Xian, Polym. Int. 2009, 58, 1435.

[43] H. Wang, H. Wang, G. Zhou, Polym. Int. 2011, 60, 557.

[44] X. Xu, Z. Song, S. Shang, S. Cui, X. Rao, Polym. Int. 2011, 60, 1521.

[45] G. Liu, G. Wu, J. Chen, Z. Kong, Prog. Org. Coat. 2016, 101, 461.

[46] L. Kong, Y. Cheng, Y. Jin, Z. Ren, Y. Li, F. Xiao, J. Mater. Chem. C. 2015, 3, 3364.

[47] Y. Wang, J. Sun, K. Jin, J. Wang, C. Yuan, J. Tong, S. Diao, F. He, Q. Fang, RSC Adv. 2014, 4, 39884

[48] Q. Ma, X. Liu, R. Zhang, J. Zhu and Y. Jiang, Green Chem. 2013, 15, 1300.

[49] F. He, C. Yuan, K. Li, S. Diao, K. Jin, J. Wang, J. Tong, J. Ma, Q. Fang, RSC Adv. 2013, 3, 23128.

[50] J. Wan, J. Zhao, B. Gan, C. Li, J. Molina-Aldareguia, Y. Zhao, Y. T. Pan, D. Y. Wang, ACS Sustain. Chem. Eng. 2016, 4, 2869.

[51] M. Hardimana, T. J. Vaughanb, C. T. McCarthya, Compos. Struct. 2017, 180, 782.

This article is protected by copyright. All rights reserved. 
[52] M. R. Vanlandingham, J. S. Villarrubia, W. F. Guthrie, G. F. Meyers, Macromol. Symp. 2001, 167, 15.

[53] K. Ohba, J. Photopolym. Sci. Tec. 2002, 15, 177.

[54] X. Niu, Y. Liu, Y. Song, J. Han, H. Pan, Carbohyd. Polym. 2018, 183, 102.

[55] T. Fang, D.A. Shimp, Prog. Polym. Sci. 1995, 20, 61.

This article is protected by copyright. All rights reserved. 


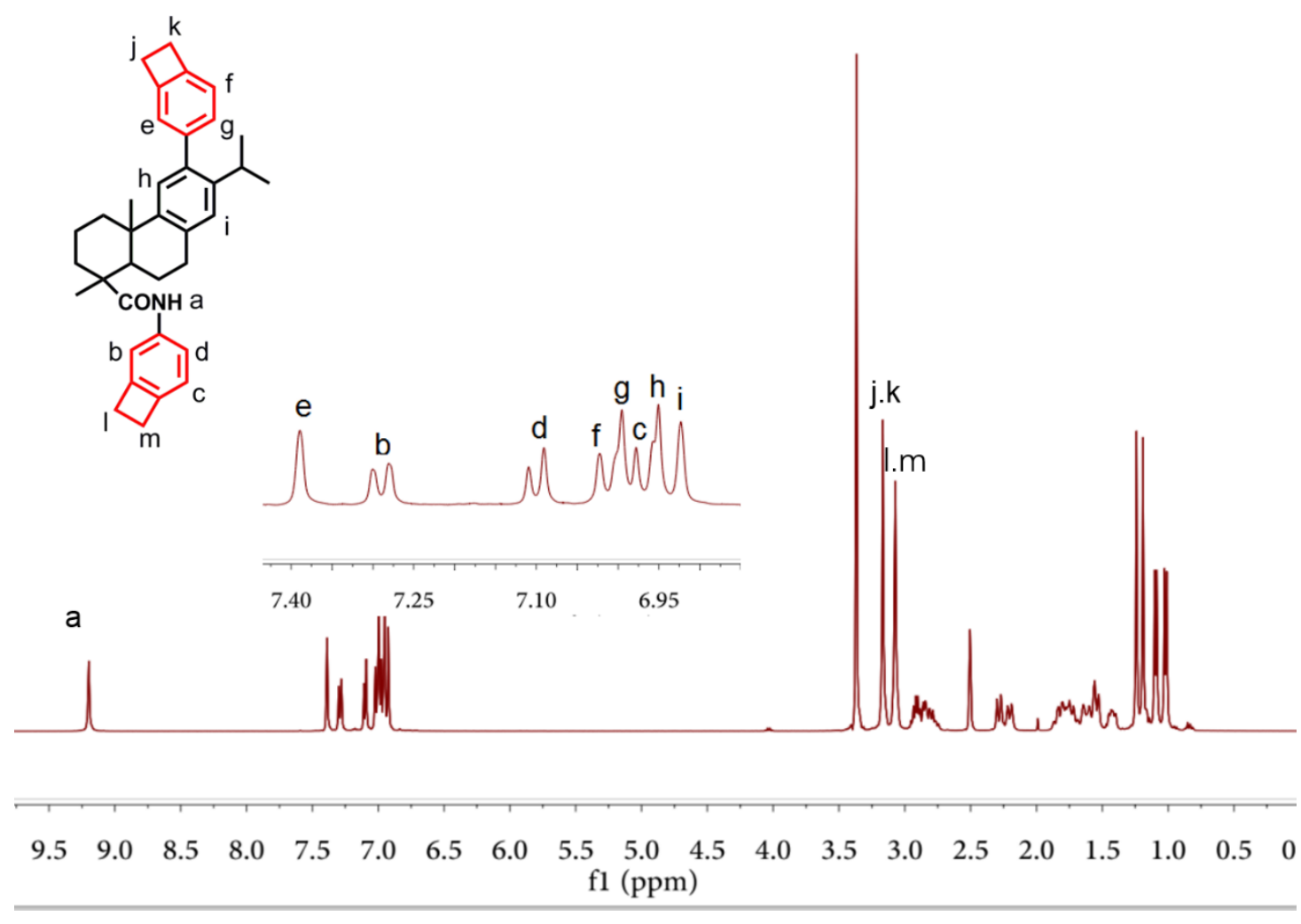

APP_48831_Figure 1.tif

This article is protected by copyright. All rights reserved. 


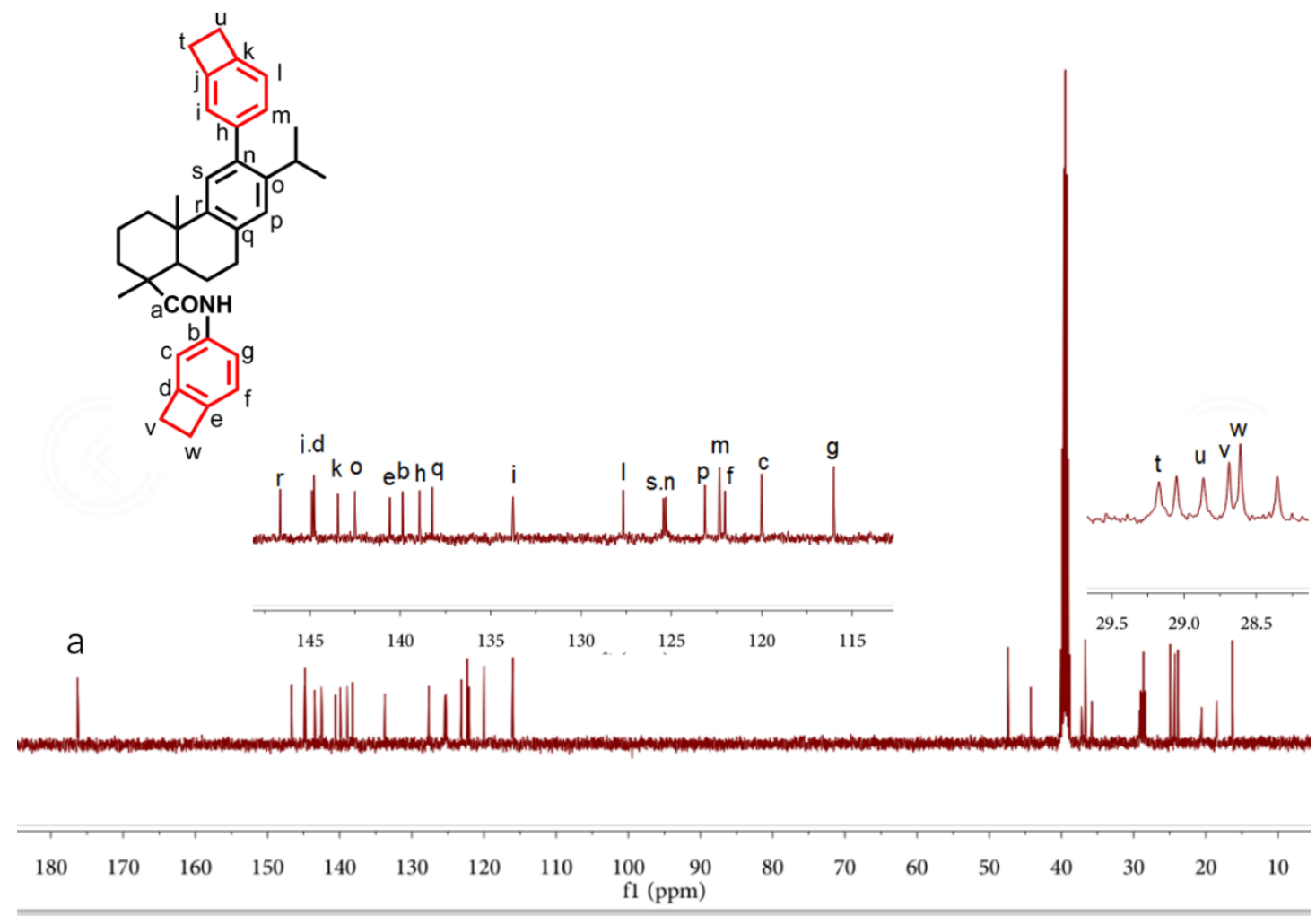

APP_48831_Figure 2.tif

This article is protected by copyright. All rights reserved. 


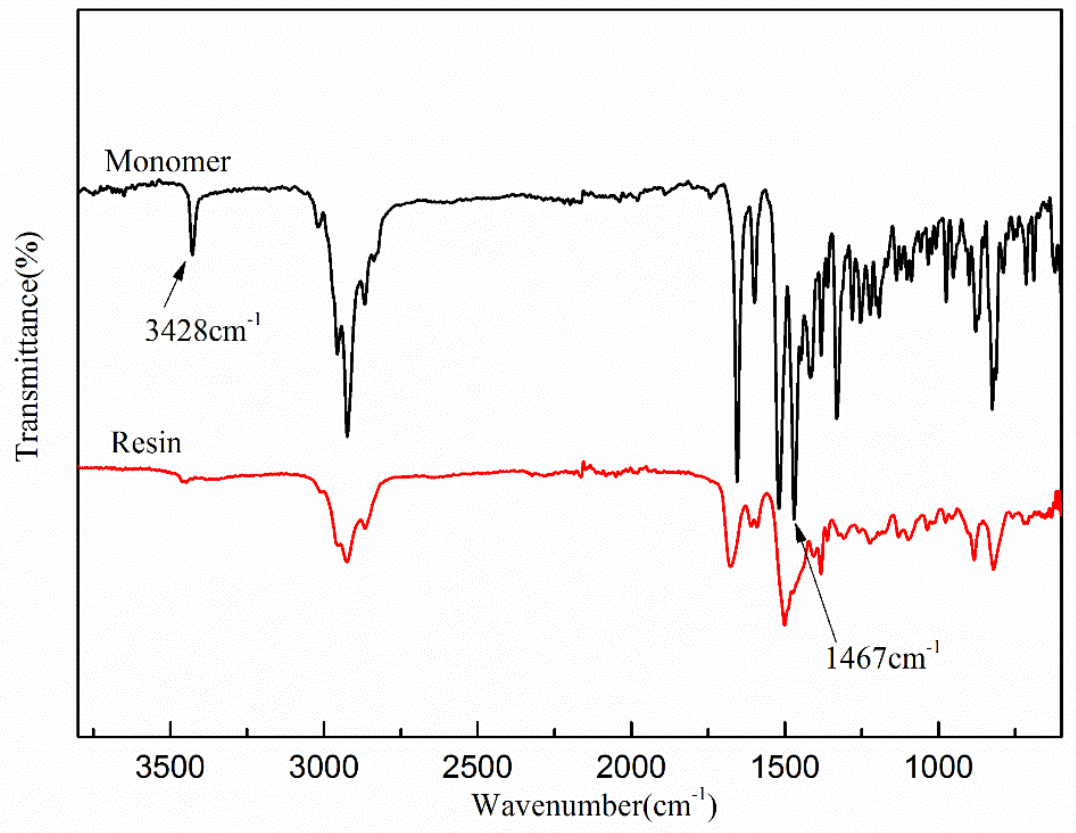

APP_48831_Figure 3.tif

This article is protected by copyright. All rights reserved. 


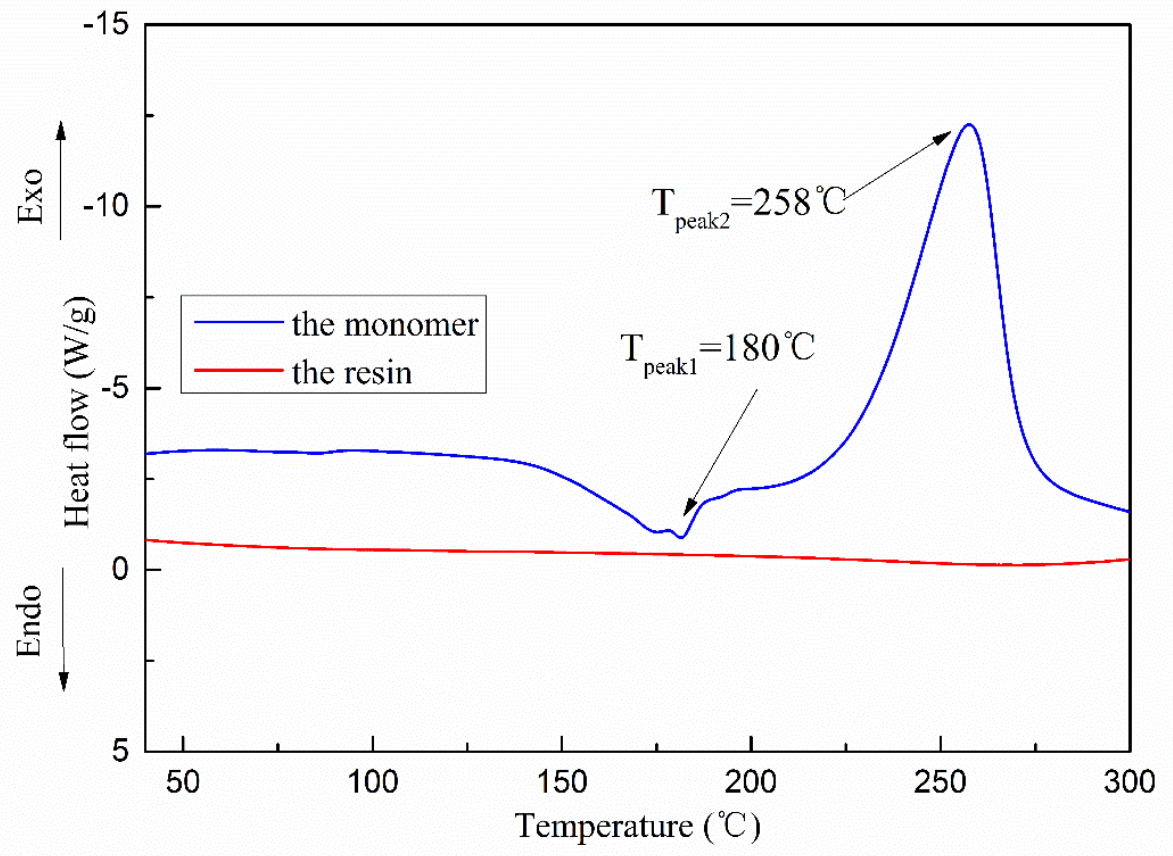

APP_48831_Figure 4.tif

This article is protected by copyright. All rights reserved. 


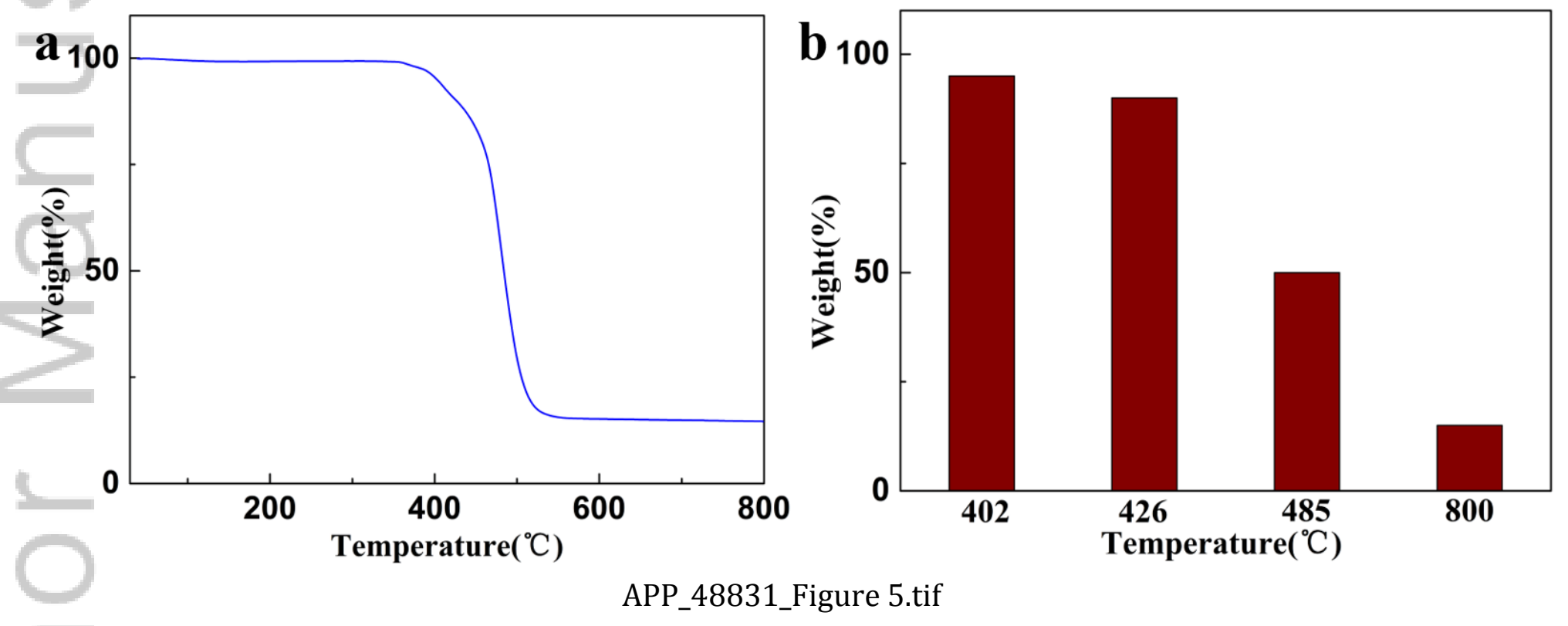

This article is protected by copyright. All rights reserved. 


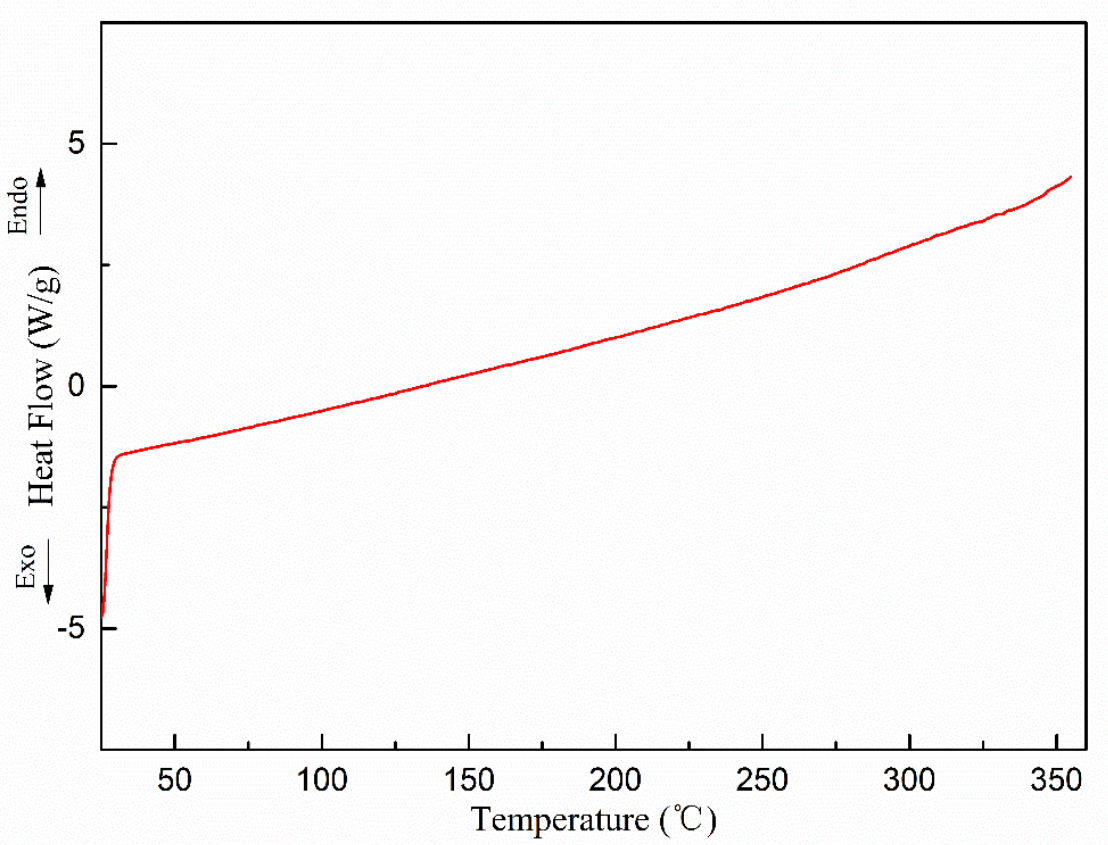

APP_48831_Figure 6.tif

This article is protected by copyright. All rights reserved. 

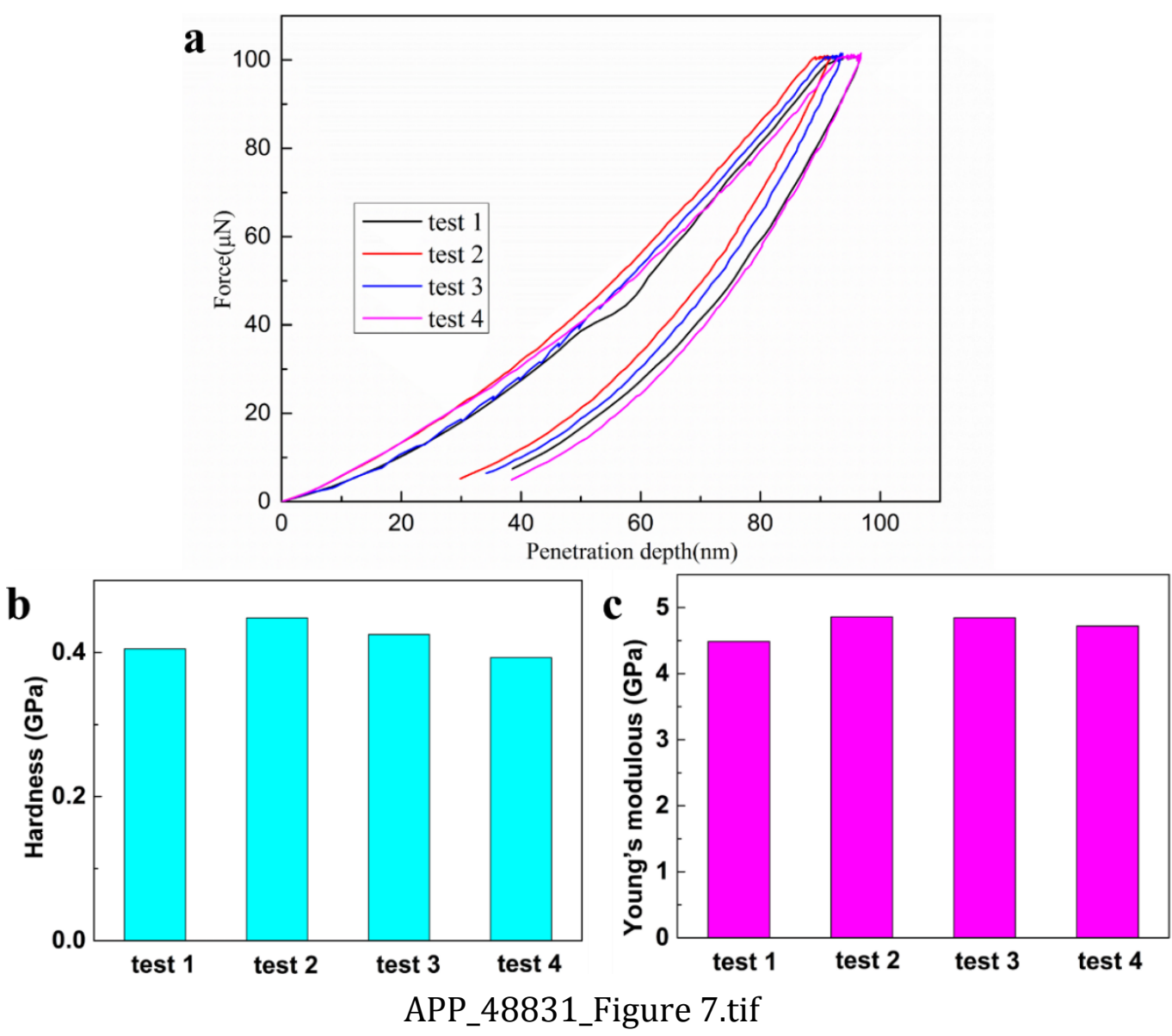

This article is protected by copyright. All rights reserved. 


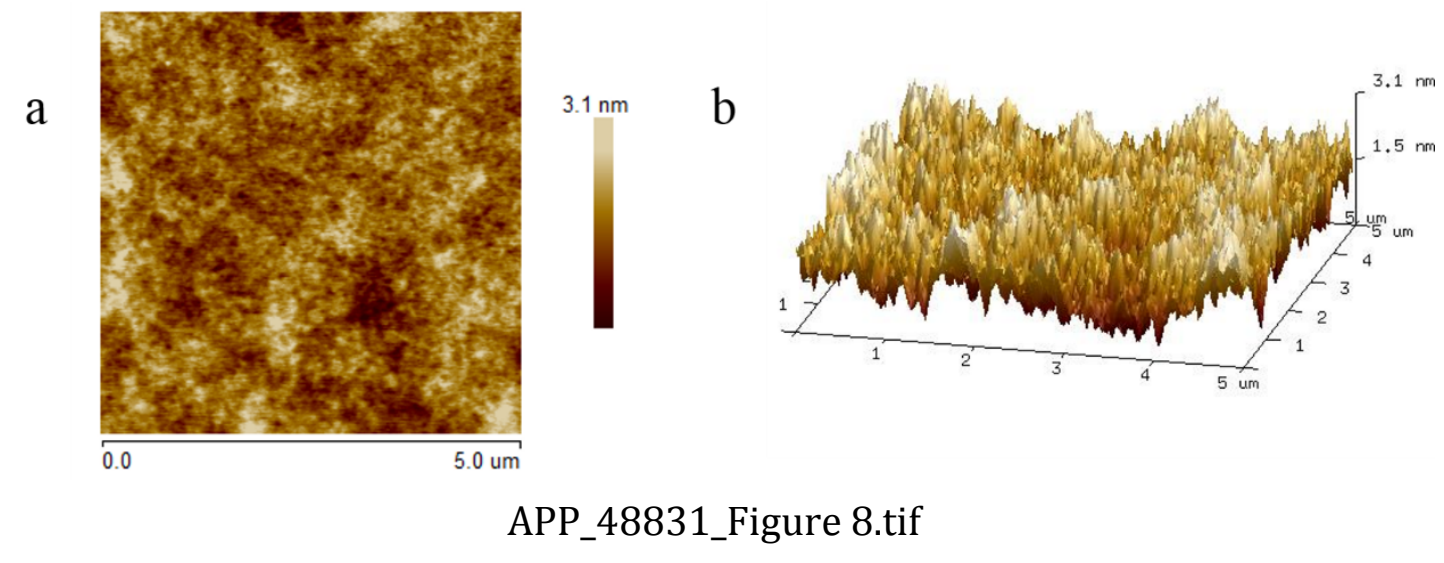

This article is protected by copyright. All rights reserved. 


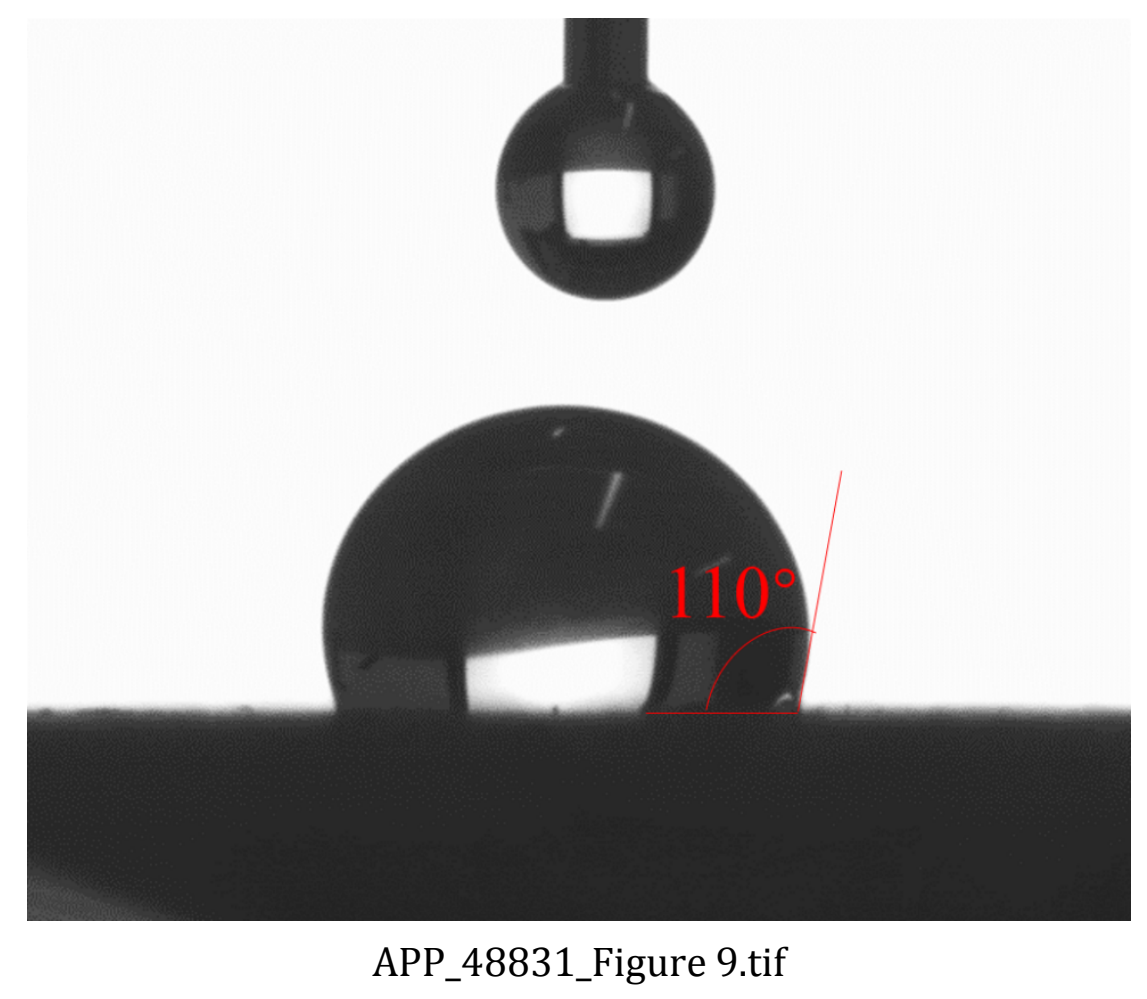

This article is protected by copyright. All rights reserved. 


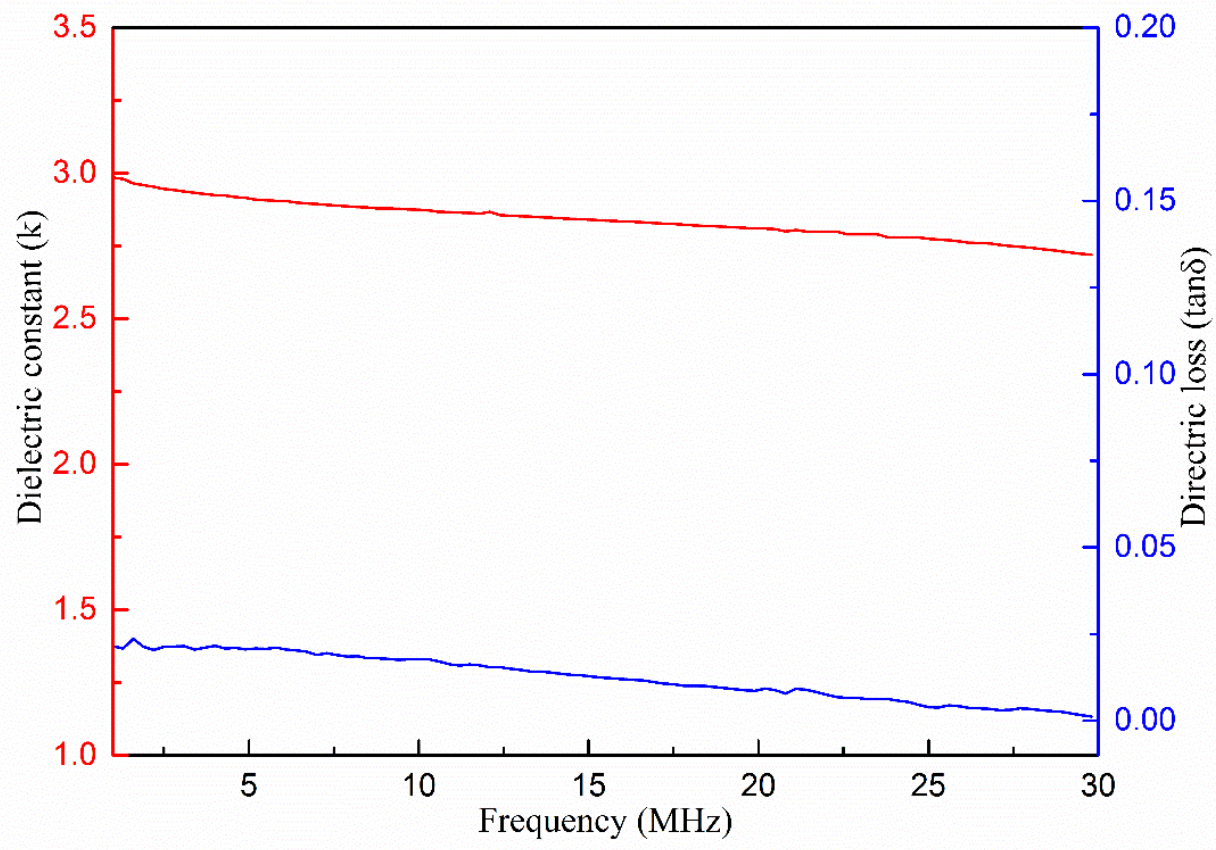

APP_48831_Figure 10.tif

This article is protected by copyright. All rights reserved. 


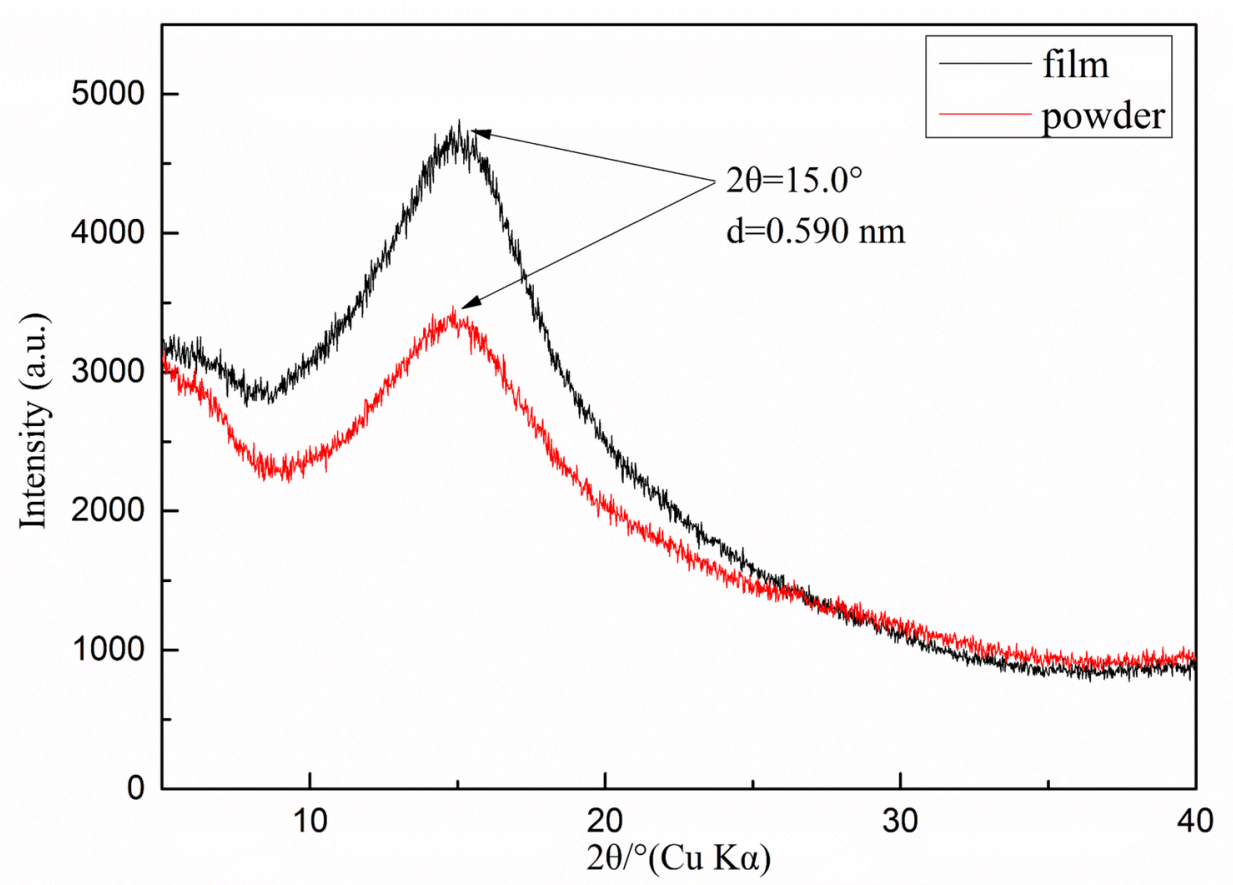

APP_48831_Figure 11.tif

This article is protected by copyright. All rights reserved. 


\section{Preparation of planar and hydrophobic benzocyclobutene based dielectric material from biorenewable rosin}

Fei Fu ${ }^{1,2}$, Dan Wang ${ }^{1,3}$, Minggui Shen ${ }^{1,3, *}$, Shibin Shang ${ }^{1,3}$, Zhanqian Song ${ }^{1, *}$, Jie Song ${ }^{4}$ A new rosin-based monomer containing bibenzocyclobutene groups was synthesized using dehydroabietic acid as the raw material. The monomer could be converted to cross-linked network via thermally ring-opening polymerization which exhibited excellent planarity and dielectric properties. These results indicate that the polymer is suitable as encapsulation resin or dielectric material in the field of electronics and microelectronics.

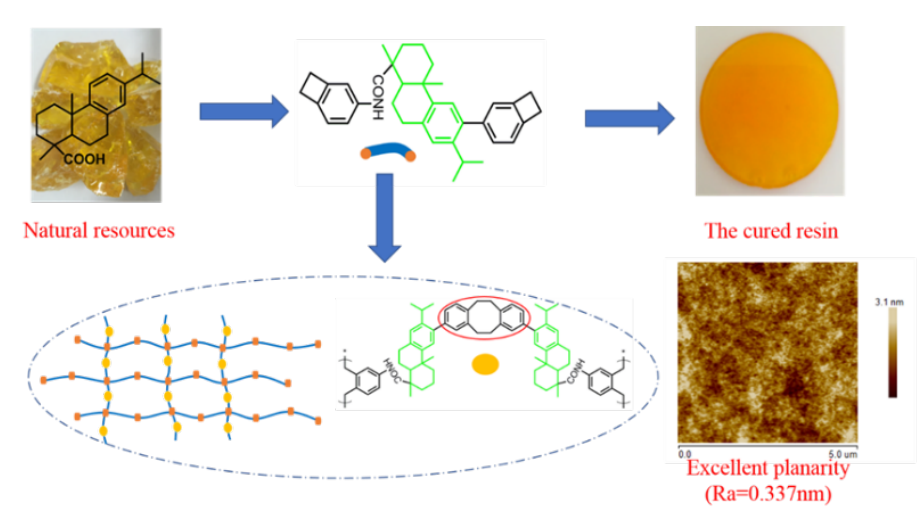

This article is protected by copyright. All rights reserved. 


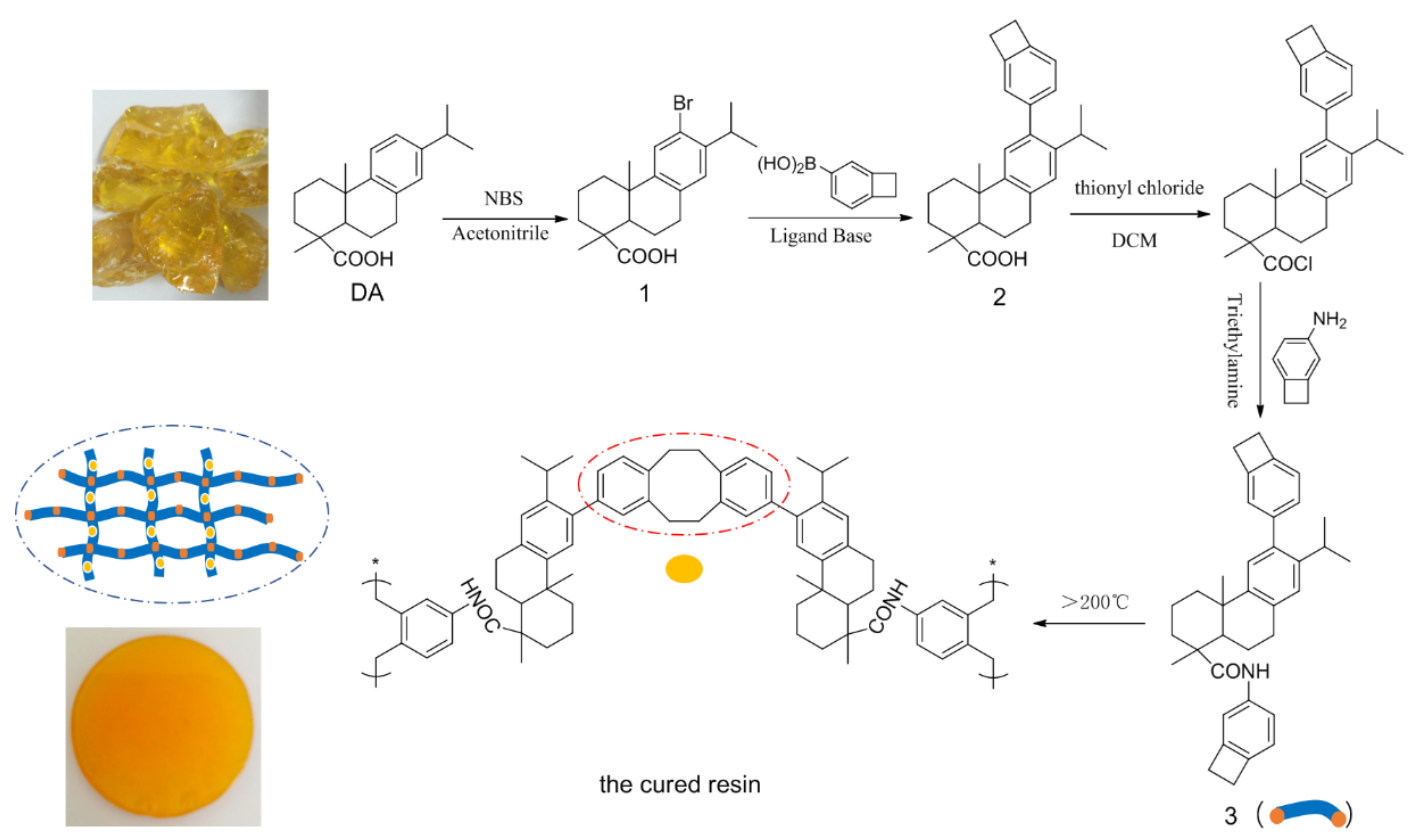

APP_48831_Scheme 1.tif

This article is protected by copyright. All rights reserved. 